\title{
İlk ve Acil Yardım Programı Yeni Mezun Öğrencilerinin Kişisel Koruyucu Donanım Kullanımına Yönelik Algı ve Saha Gözlemleri
}

\author{
Perception and Field Observations of New Graduates of First and \\ Emergency Aid Program regarding the Use of Personal Protective
}

Equipment

\author{
Ayfer YÜKSEL ${ }^{1}$ \\ ${ }^{1}$ Dr. Öğr. Üyesi, Ufuk Üniversitesi Sağl1k Hizmetleri Meslek Yüksekokulu, ANKARA \\ ORCID ID: 0000-0003-3140-1432 e posta: drayferercan@yahoo.com
}

Geliş tarihi/Received:06.05.2021

Kabul tarihi/Accepted:23.08.2021

Yayın tarihi/Online published:15.12.2021

DOI: $10.54862 /$ pashid.933979

\section{ÖZET}

Amaç: İlk ve Acil Yardım Teknikerliği Programı'ndan yeni mezun öğrencilerin kişisel koruyucu donanım (KKD) kullanımına yönelik alg1 ve saha gözlemlerinin incelenmesidir.

Yöntem: Tarama modeli kullanılmıştır. Veri toplama aracı olarak araştırmacı tarafından geliştirilen anket kullanılmış, Etik Kurul onayı alınmış, çevrimiçi uygulanmıştır. Ankette kişisel bilgi formu ve alg1/bilgi ve gözlemleri belirlemeye yönelik toplam 24 soru bulunmaktadır. Çalışma grubu, bir Vakıf Üniversitesi Sağlık Hizmetleri Meslek Yüksekokulu'ndaki İlk ve Acil Yardım Programı'ndan 2019-2020 eğitim-öğretim yılı yeni mezun olan toplam 39 öğrenciden oluşmaktadır. Katılımcıların \%59 'u kadın, \%41'i erkektir.

Bulgular: Katılımcıların yaklaşık \%90'ının KKD'lerin kullanımına ilişkin doğru bilgiye sahip oldukları; iki katılımcıdan birisinin KKD kullanımında giyim sırasını doğru açıkladığı, on katılımcıdan dokuzunun cerrahi maske ve kullanım süresi ile ilgili doğru bilgiye sahip oldukları belirlenmiştir. On katılımcıdan altısı da "gözlük ve yüz koruyucular" ile ilgili doğru bilgiye sahiptir. Üç katılımcıdan biri Covid-19 gibi yüksek bulaş riski olan enfeksiyon hastalıklarında önlük kullanımı ile ilgili sıralamayı doğru yapmaktadır. Uygulamalardaki gözlemlerine göre diğer sağlık çalışanlarının \%10'u "her vakada”, yaklaşık \%50'si ise "sıklıkla" KKD kullanmaktadır.
Katılımciların yarısı uygulamadaki gözlemlerinin/rol modellerin kendi KKD kullanımına ilişkin düşüncelerine "çok etkili" olduğunu söylemişlerdir. Uygulamalarda "hiç tedirgin" (\%75) olmadıklarını ve "biraz tedirgin" (\%60) olduklarını ifade etmişlerdir.

Sonuç: Katılımcıların KKD ile ilgili bilgi kaynakları teorik dersler ve saha uygulamalarıdır. KKD'lerden cerrahi maske ve eldiven ile ilgili teorik ve pratik doğru bilgiye sahip olanların oranı yüksek; siperlik, yüz koruyucu, gözlük, önlük gibi diğer KKD'ler ve bunların bir arada kullanım talimatları ile ilgili bilgiye sahip olanların oranı düşüktür. Uygulamalardaki diğer sağlık çalışanlarının KKD kullanım sıklıkları değişmektedir. KKD kullanımında gözlemleyerek öğrenmenin "çok etkili" olduğu, ayrıca katılımciların saha uygulama ortamlarında kendilerini güvende hissettikleri anlaşılmıştır.

Bu çalışma literaratüre katkısının yanında SHMYO programlarındaki teorik ve uygulamalı derslerin KKD kullanımının önemine ağırlık verilecek şekilde düzenlenmesi ile iş sağlı̆̆ 1 ve güvenliği uygulamalarında katkı sağlayabilir.

Anahtar Kelimeler: Kişisel Koruyucu Donanım, İlk ve Acil Yardım Teknikerliği Programı, Yeni mezun öğrenci 


\section{ABSTRACT}

Objective: To examine the PPE perception and field observations of new graduates from the First and Emergency Aid Technician program.

Materials and Methods: Scanning model is used. As a data collection tool, the researcher created a questionnaire, and received the Ethics Committee's approval. The study group consists of 39 new graduates from the First and Emergency Aid Program (2019-2020) at the Vocational School of Health Care Services.

Results: $90 \%$ of the participants had the correct information regarding the usage of "PPE," and one of the two participants correctly explained the order of wearing the PPE, and $90 \%$ of the participants had the correct information about the surgical mask and the duration of use. Six of every ten participants had the proper knowledge on "goggles and face shields". One out of every two participants properly explained the order of wearing PPE. One of the three participants make the correct order regarding the use of aprons in infectious diseases with high transmission risk such as Covid-19. 10\%

\section{GİRİŞ}

Ambulans ve Acil bakım Teknikerleri; Covid-19 gibi biyolojik ayrıca ergonomik, fiziksel ve çevresel riskler başta olmak üzere birçok riskle karşı karşıyadır. Hasta ile ilk karşılaşan sağlık personelleri olduklarından bu riskleri en aza indirmek için Kişisel Koruyucu Donanım (KKD) kullanımı en yoğun gruplardandır. Kan, vücut çıkartıları, temas ve solunum yoluyla bulaşma riski taşıyan hastalıklara bulaşların önlenmesi ve sağlık çalışanlarının güvenliğine yönelik kullanılan özel giysi ve ekipmanlar Kişisel Koruyucu Donanım, Kişisel Koruyucu Ekipman veya Kişisel Koruyucu Malzeme (KKD/KKE/KKM) olarak adlandırılmaktadır. Sağlık alanında en yaygın kullanılan KKD türleri ise eldiven, önlük, maske/respiratörler, gözlükler ve siperliklerdir (Yıldırım ve Gerdan, 2017; Beşer ve Topçu, 2013). of other health care workers use PPE "for every case" and 50\% use "frequently." Half of the participants said that their observations/role models in practice were "very influential" on their thoughts on their PPE use. Practices are that there is no "anxiety" (75\%) and "a little anxiety" (60\%).

Conclusion: Theoretical lessons and field applications are the participants' primary sources of PPE knowledge. The rate of those who have both theoretical and practical knowledge about surgical masks and gloves is high; the rate of those who have knowledge about other PPE such as visor, face protector, goggles, apron and the instructions for using them together is low. Observational learning is "very effective" for PPE use, and participants feel safe.

In addition to the study can be used in OHS practices by arranging the theoretical and practical lessons in HSVS programs in a way that emphasizes the importance of PPE use.

Keywords: Personal Protective Equipment, Department of First and Emergency Aid Technician, New graduate

\section{Bakanlığı'nca yayınlanan "Kişisel Koruyucu} Donanımların İşyerlerinde Kullanılması Hakkındaki Yönetmelik'te” KKD'ler “işyerindeki risklerin önlenmesinin veya azaltılmasının, teknik tedbirlere dayalı toplu korunma ya da iş organizasyonu veya çalışma yöntemleri ile sağlanamadığı durumlarda kullanılacak "araçgereç” olarak belirtilmektedir. Sağlık çalışanları, KKD’leri doğru kullanmakla, korumakla, uygun yerlerde ve uygun şekilde muhafaza etmekle yükümlüdür (Türk Tabipler Birliği, Sağlık Çalışanları İçin İşçi Sağlığı ve Güvenliği, 2014).

2013 tarih 28695 sayılı Resmî gazetedeki Çalışma ve Sosyal Güvenlik Bakanlığı'ndan; Kişisel Koruyucu Donanımların İş Yerlerinde Kullanılması Hakkındaki Yönetmeliğin 5.maddesinde belirtildiği gibi; KKD, risklerin, toplu korunmayı sağlayacak teknik önlemlerle veya iş 
organizasyonu ve çalışma yöntemleriyle önlenemediği, tam olarak sınırlandırılamadığı durumlarda, iş kazası ya da meslek hastalığının önlenmesi, çalışanların sağlık ve güvenlik risklerinden korunması, sağlık ve güvenlik koşullarının iyileştirilmesi amacıyla kullanılır. (T.C. Resmî Gazete-2 Temmuz, 2013, sayı: 28695).

1 Mayıs 2019 tarih 30761 sayılı Aile, Çalışma ve Sosyal Güvenlik Bakanlığg’nın Kişisel Koruyucu Donanım Yönetmeliği’nde: KKD’lerin tasarımı ve üretiminde, kullanıcıların sağlık ve güvenliğinin korunması ile KKD'lerin serbest dolaşımına ilişkin usul ve esasları belirlemektedir. (T.C. Resmî Gazete-1 Mayıs 2019, sayı: 30761).

Ülkemizde sağlık çalışanları iş sağlığı ve güvenliği yönünden 20.06.2012 tarih ve 6331 sayılı iş sağlığı güvenliği kanunun ve Aile, Çalışma ve Sosyal Güvenlik Bakanlığı'nın 29.03.2013 tarih ve 28602 tarihli resmî gazetedeki tebliğ ile tehlikeli iş kolu sınıfında yer almıştır (T.C. Resmî Gazete- 30 Haziran 2012, say1: 28339).

Dünyada ve ülkemizde iş güvenliği ve çalışan sağlığı kapsamında çalışanların KKD kullanımları ile ilgili birçok çalışma yapılmıştır. Örneğin Kahya E. ve arkadaşlarının 2019 yılındaki "Metal endüstrisinde kişisel koruyucu kullanımının analizi" çalışmasında; iş kazalarını engellemek için KKD kullanımının sağlayacağı katkının eğitimler ile sağlanması gerektiği sonucuna varılmıştır (Kahya, Ulutaş ve Özkan, 2019).

Demirbilek ve arkadaşlarının "KD Kullanımını Etkileyen Bireysel ve Örgütsel Değişkenler” başlıklı çalışması; çalışanların "güvenli davranış" sergilemelerinde güvenlik ihtiyacı hissetmelerinin ne denli önemli olduğunu ortaya koymaktadır (Demirbilek ve Çakır, 2008).

Pandemiye yol açan Covid-19'la ilgili yapılan başka bir çalışmada; sağlık çalışanlarına bulaş için risk faktörlerine bakıldığında; Wuhan'da
330 yataklı üniversite hastanesinde görevli Covid19 tanısı konulan 28 ile 34 enfekte olmayan sağlık çalışanı karşılaştırılarak risk faktörleri araştırılmış, Covid-19 gelişmesine etki eden faktörlere bakıldığında uygunsuz KKD kullanımının enfekte olma olasılığını 2,8 kat artırdığı görülmüştür. KKD'lerin başında gelen maskenin (cerrahi, tıbbi maske); Covid-19 gibi pandemi dönemlerinde toplu alanlar, hasta hizmeti verilen yerler ve hatta ofis ve dinlenme alanlarında bile sağlık çalışanları tarafından kullanılması önerilmektedir. Hastane gibi sağlık hizmeti alanlarında sadece sağlık çalışanları değil, hastaneye gelen ve hastanede yatan solunum yetmezliği gibi maskeyi tolere edemeyen hasta grubu dişında herkesin maske kullanması önerilmektedir (Metan,2020).

Yine bu pandemi döneminde KKD kullanımının etkisini gösteren 13-16 Mart 2020'de İtalya'da yapılan bir çalışmada; bir üniversite hastanesinde görev yapan üç hemşirede (ikisi kız kardeş ve diğerinin de kız kardeşinde daha önce Covid-19 olan hemşireler) Covid-19 saptanmış olup semptomları başlamadan önce üç vardiya, başladıktan sonra bir vardiya görev yaptıkları belirlenmiştir. Bu hastanede bulunan hasta ve sağlık çalışanları düzenli maske takmaktadır. $\mathrm{Bu}$ üç hemşire ile temaslı olan 29 hasta,107 sağlık çalışanı PCR ile taranınca aynı vardiyadaki bir hemşire dışında pozitif olgu saptanmamıştır. Yani hasta ve çalışanların maske takmaları ve el hijyenini sağlamaları muhtemelen bu hastanedeki Covid19'lu üç hemşire nedeniyle kurum içinde oluşabilecek salgını önleyecek basit ve etkili bir yöntem olarak karşımıza çıkmaktadır (Metan,2020). Covid-19 pandemisinde T.C. Sağlık Bakanlığg'nın verilerine göre Ağustos (2020) sonu itibari ile bir milyon altmış bir bin altı yüz otuz beş sağlık çalışanımızdan dan yirmi dokuz bin sekiz yüz altmış beş sağlık çalışanımıza virüs 
bulaşırken elli iki sağlık çalışanımız da hayatını kaybetmiştir. Bu çalışma ile mevcut durumun saptanıp KKD'lerin sağlık çalışanları için iş sağlığı ve güvenliği yönünden bulaş riskini azaltmadaki önemi vurgulanarak SHMYO eğitim programlarında buna yönelik düzenlemelerin yapılmasına katkı sağlayacaktır.

\section{MATERYAL METOT}

Nicel bir çalışma olan bu araştırmada tarama modeli kullanılmıştır. Tarama modelleri; geçmişte ya da halen var olan bir durumu var olduğu şekliyle tespit etmeyi amaçlayan araştırma modelidir (Karasar, 2018). Veri toplama arac1 olarak araştırmacı tarafından geliştirilen anket kullanılmıştır. Anket için Ufuk Üniversitesi Etik Kurulu'ndan onay alınmıştır. Anket sorularının hazırlanmasında öğrencilerle yapılan birebir görüşmeler ve bu alanda yapılmış benzer çalışmalardan yararlanılmıştır (Gazi Üniversitesi Mezun Görüş Anketi,2017). Anket geliştirme sürecine uygun olarak geliştirilmiştir. Ankette 4 sorudan oluşan kişisel bilgi formu ile bilgi ve gözlemleri belirlemeye yönelik 20 soru olmak üzere toplam 24 soru bulunmaktadır. Evrenin tamamına ulaşıldığı için örneklem alınmamıştır. Araştırmanın çalışma grubu bir Sağlık Hizmetleri Meslek Yüksek Okulu'ndaki 2019-2020 eğitim-öğretim yılı Bahar dönemi İlk ve Acil Yardım Programı'ndan yeni mezun toplam 39 öğrenciden oluşmaktadır. Katılımcılara ait tanımlayıcı bilgiler Tablo 1'de verilmektedir.

Veri toplama aracı öğrencilere araştırmacı tarafından çevrim içi (online) uygulanmıştır. Uygulama öncesi öğrenciler uygulama süreci hakkında bilgilendirilmiştir.

Kişisel koruyucu donanım kullanımı ile ilgili bilgi ve gözlemleri belirlemeye yönelik olan sorulardan iki tanesi (online form oluşturma sürecinde hatalı giriş nedeniyle 5 ve 15.soru) analizden çıkartılmıştır. Dört kişisel soru ve 18 adet bilgi ve gözlemleri belirlemeye yönelik olmak üzere toplam 22 soruya verilen yanıtlar yüzde olarak analiz edilmiştir.

Katılımciların \%59'u kadın, \%41 ‘i erkektir. Yüzde 62'si Sağlık Meslek Lisesi, geri kalanı Anadolu Lisesi ve diğer liselerden mezun olmuşlardır. Katılımcıların \%74'ü eğitim aldıkları Üniversite Hastaneleri, geri kalanı bir Devlet Hastanesi ya da diğer bir Sağlık Merkezi'nde uygulama yaptıklarını belirtmişlerdir. Katılımcıların yüzde 46'sı eğitim aldıkları Üniversite Hastaneleri yüzde 54'ü diğer bir Sağl1k Merkezi (Üniversite, Devlet Hastaneleri veya başka bir Sağlık Merkezi)'nde staj yapmıştır.

Tablo 1: Katılımcılara ait tanımlayıcı bilgiler

\begin{tabular}{lcc}
\hline & $\mathrm{n}$ & $\%$ \\
\hline Cinsiyet & & \\
\hline Kadın & 23 & 58,97 \\
Erkek & 16 & 41,02 \\
\hline Mezun olunan okul & & \\
\hline Anadolu Lisesi & 10 & 25,64 \\
Sağlık Meslek Lisesi & 24 & 61,53 \\
Diğer & 5 & 12,82 \\
\hline Uygulama yapılan yer & & \\
\hline Bir Devlet Hastanesi & 8 & 20,51 \\
Diğer Bir Sağlık Merkezi & 2 & 5,12 \\
Ufuk Üniversitesi Hastanesi & 29 & 74,35 \\
\hline Staj yapılan yer & & \\
\hline Ufuk Üniversitesi Hastanesi & 10 & 25,64 \\
Bir Devlet Hastanesi & 18 & 46,15 \\
Diğer Bir Sağlık Merkezi & 11 & 28,18 \\
(112, İstasyon) & & \\
\hline
\end{tabular}




\section{BULGULAR}

Araştırmada ilk soru Kişisel Koruyucu Donanım (KKD) ve kullanımına ilişkin bilgi kaynaklarınız en çok hangisidir? şeklinde ifade edilmiştir. Katılımcıların \%59'u kişisel koruyucu donanım ve kullanımına ilişkin bilgi kaynaklarının "uygulamalı dersler, staj vb. gibi saha uygulamaları”, \%31'i “Sağlık Hizmetleri Meslek Yüksek Okulu'ndaki teorik dersler" ve geri kalan $\% 10$ 'u ise "kaynak kitaplar" olduğunu belirtmiştir.

Araştırmada ikinci soru; KKD' lerin kullanımına ilişkin aşağıdakilerden hangisi doğrudur? şeklinde ifade edilmiştir. $\mathrm{Bu}$ soruya katılımcıların \%87'si “sağlık çalışanlarının hastalık riskini azalttığı” için kullanıldığını belirterek doğru cevap vermişlerdir.

Araştırmada üçüncü soru $K K D$ ' lerin neden kullanıldı̆̆ı ile ilgili düşünceniz nedir? şeklinde soruldu. İkinci soruda olduğu gibi katılımcıların \%87'si “sağlık çalışanlarının hastalık bulaş riskini azalttığı için” cevabını vermişlerdir.

Dördüncü soru, KKD sağlık çalışanını nelere karşı koruyamaz? şeklinde ifade edilmişti. Katılımcılar \% 87 ile "trafik kazaları ve doğal afetler” doğru cevabını vermişlerdir.

Katılımcıların Aşă̆ıdakilerden hangisi sağlık çalışanı için kullanılan KKD' lerden değildir? sorusuna \%95'i “enjektör" cevabı ile doğru cevabı vermiştir. Başka bir anlatımla katılımcıların \%95'i sağlık çalışanı için kullanılan KKD adlarını bilmektedir.

Araştırmada sorulan altıncı soru Aşağldakilerden hangisi sağlık çalışanının hastalık riskini azaltmada birlikte kullanıldı ğında en etkin olacaktır? şeklinde soruldu. $\mathrm{Bu}$ soruya katılımcıların \% 92'si “tulum, maske, siperlik, eldiven" seçeneğiyle doğru cevabı verdi.

Covid-19 pandemisi gibi salgınların olduğu dönemlerde aşağıdakilerden hangisi maskenin kullanım talimatı ile ilgili yanlıştır? şeklinde sorulan yedinci soruya katılımcıların \%80'i “sadece enfekte (hasta) olan sağlık çalışanlarının maske takmaları toplum koruyuculuğu açısından yeterlidir” seçeneği ile doğru cevabı vermiş, katılımcıların \%18'i ise "toplu ve kalabalık alanlarda takmaları gereklidir" seçeneğini işaretlemiştir.

Araştırmada Cerrahi maske ile ilgili aşağıdakilerden hangisi yanlıştır? şeklinde sorulan (8. soru) soruya katılımcıların \%90’ı doğru cevap (aile bireyleri ile ortak kullanım dışında ortak kullanılmamalı) vermiștir.

Araştırmada kullanılan dokuzuncu soru Aşă̆ıdakilerden hangisi cerrahi maskenin kullanım süresi ile ilgili doğrudur? $\mathrm{Bu}$ soruya katılımcıların \%92'si “süresi tam olarak bilinmemekle birlikte yaklaşık 6-8 saat olup tek kullanımlıktır" seçeneği ile doğru yanıtı vermişlerdir.

Aşağıdakilerden hangisi gözlük ve yüz koruyucuları ile ilgili yanlıştır? şeklinde ifade edilen onuncu araştırma sorusuna katılımcıların yüzde 62'si 'tek kullanımlıktır' cevabı ile doğru cevabı verirken; \%21'i “özel bir uyarı yoksa etil alkolle dezenfekte edilerek uygun ortamda kendi kendine kurumak üzere birakılmalıdır" cevabını, \%13’ü ise "tekrar kullanılabilir özellikteki gözlükler ve yüz koruyucuları üretici firmanın önerisine uygun olarak temizlenir" cevabını vermiştir.

Araştırmada on birinci soru Kişisel koruyucu donanım kullanımında giyme sirası hangi şekilde olmalıdır? şeklinde soruldu. $\mathrm{Bu}$ soruya katılımcıların sadece $\% 51$ 'i “önlük, maske, gözlük, eldiven” seçeneği ile doğru cevabı verirken, geri kalan \%49'u diğer yanlış olan üç seçenekten birisini işaretlemiştir. 
On ikinci soru, Cerrahi maske kullanımı ile ilgili sıralamada hangisi yanlıştır?" şeklinde ifade edildi. Katılımcıların \%64'ü bu soruya doğru cevap (maskenin üst tarafındaki metal şerit çenenin üstüne hafifçe bastırılarak yerleştirilir) vermiş, \%36's1 diğer yanlış seçenekleri seçmişlerdir.

$$
\text { Eldiven kullanımı ile ilgili }
$$
aşağıdakilerden hangisi yanlıştır? şeklinde ifade edilen on üçüncü soruya katılımcıların \%74'ü "işlem sonrası eller eldivenli olarak yıkanmalıdır" doğru cevabını vermiştir.

Covid-19 gibi yüksek bulaş riski olan enfeksiyon hastalıklarında önlük kullanımı ile ilgili sıralamada aşă̆ldakilerden hangisi yanlıştır? şeklinde sorulan on dördüncü soruya katılımcıların sadece \%37'si doğru cevap olan "yıkanması için kirli kutusuna atın" cevabını verirken, \%13’ü “önlüğün önü ve kollar1 kontaminedir", "önlüğü çıkarırken elleriniz kontamine olursa hemen ellerinizi yıkayın ya da alkol bazlı bir el antiseptiği kullanın”, “önlüğün iç kısmını dışa çevirin" ve "sararak toplayın" seçeneklerinden birini cevap olarak işaretlemiştir.

Katılımcilar, Uygulama ve/ veya staj gibi saha çalışmalarında kişisel koruyucu donanım kullanım durumunuzla ilgili olarak aşă̆ldakilerden hangisi doğrudur? sorusuna (15. Soru) \%46 ile "her vakada kullandım" cevabı verilirken, \%33’ü “sıklıkla kullandım”, \%15’i “ara sıra kullandım" geri kalan \%5'i ise "hiç kullanmadım" cevabını vermiştir.
Araştırmada on altıncı soru, Uygulama ya da staj gibi saha çalışmalarında diğer să̆lık çalışanlarının kişisel koruyucu donanım kullanım sıklı̆̆ını sizin gözleminize göre aşă̆ıdakilerden hangisi ile tanımlarsınız? şeklinde soruldu. Bu soruya katılımciların \%13’ü “her vakada kullanıyorlardı" diye cevaplarken, \%49'u “s1klıkla kullanıyorlardı" \%33'ü "ara sira kullanıyorlardı" ve kalan \%5'i "hiç kullandıklarını görmedim" şeklinde cevaplamıştır.

Katılımcıların, Sahada gördüğünüz uygulamalar sizin kişisel koruyucu donanım kullanımı ile ilgili düşüncelerinizde ne kadar etkili oldu? (17. soru) sorusuna \%54'ü "çok etkili oldu" derken, \%31'i “az çok etkili oldu” geri kalan \%15 ' $\mathrm{i}$ ise "hiç etkili olmadı" şeklinde yanıtladı. Yani yaklaşık \%85 katılımcı saha uygulamalarının KKD kullanımı ile ilgili düşüncelerine etki etti ettiğini belirtti.

Araştırmada son soru (18.) Eğitim döneminiz süresinde uygulamalar sirasında sahada çalışırken kendi güvenliğiniz konusunda nasıl hissettiniz? şeklinde ifade edildi. Bu soruya katılımcıların \%44'ü "hiç tedirginlik hissetmedim" seçeneğini işaretlerken, \%56’s1 ise “biraz tedirginlik hissettim" seçeneğini işaretlemiş "çok tedirgin oldum" seçeneğini hiçbir katılımcı işaretlememiştir. $\mathrm{Bu}$ soruya verilen yanıtlara bakarak katılımciların saha uygulamalarında çalıştıkları ortamlarda kendilerini güvende hissettiklerini söyleyebiliriz.

\section{TARTIŞMA}

Kişisel koruyucu donanım; risklerin, toplu korunmayı sağlayacak teknik önlemlerle veya iş organizasyonu ve çalışma yöntemleriyle önlenemediği, tam olarak sınırlandırılamadığı durumlarda, iş kazası ya da meslek hastalığının önlenmesi, çalışanların sağlık ve güvenlik risklerinden korunması, sağlık ve güvenlik koşullarının iyileştirilmesi amacıyla kullanılmalıdır.

Ülkemizde iş güvenliği ve çalışan sağlığının önemli bir parçası olan çalışanların kişisel koruyucu 
donanım kullanımı ile ilgili yönetmelik ve düzenlemeler ile bu konuda standardizasyon sağlanmaya çalışılması amaçlanmaktadır.

İşverenin işçiyi gözetme borcu kapsamında iş sağlığ1 güvenliğine ilişkin gerekli önlemleri alarak, güvenli bir iş yeri ortamı sağlama yükümlülüğü vardır. Bu yükümlülükler 4857 Sayılı İş Yasasının 77-89'uncu maddelerini kapsayan beşinci bölümünde ve Borçlar Yasası'nın 55. Maddesinde belirtilmiştir.4857 Sayılı İş̧ Yasası'nın 78.maddesine dayanılarak çıkartılan Kişisel Koruyucu Donanım Yönetmeliği gereği iş yerindeki risklerin önlenmesi ya da azaltılması teknik sistemler, iş organizasyonu ve çalışma yöntemleri ile sağlanamadığında, kişisel koruyucular devreye girmektedir (Deveci, 2012).

$\mathrm{Bu}$ çalışmada; sağlık alanında kullanılan KKD'lerden cerrahi maske ve daha sonra da eldiven ile ilgili hem teorik hem de kullanım talimatı ile ilgili doğru bilgiye sahip olanların oranı yüksek iken; siperlik, yüz koruyucu, gözlük, önlük gibi diğer kişisel koruyucu donanımlar ve özellikle de bunların bir arada kullanılması gereken durumlardaki kullanım talimatları ile ilgili uygulamaya yönelik bilgiye sahip olanların oranının düşük olduğunu söylemek mümkündür. Ayrıca katılımcıların sahada gördükleri uygulamalara göre KKD kullanımlarını belirlediklerini ve katılımcıların saha uygulamalarında cerrahi maske kullanımını daha fazla gözlemledikleri için bununla ilgili daha çok bilgi sahibi olduklarını; diğer KKD’lerle ilgili ise daha az gözlem ve deneyime sahip olduklarını söyleyebiliriz.

Çalışmada elde edilen bulgulara baktığımızda; katılımcıların KKD ile ilgili bilgilerinin büyük bir kısmını üniversite eğitimi sırasında teorik ve uygulamalı dersler ile edindiklerini ve KKD'lerin genel kullanım amaçları ile ilgili teorik bilgilerinin oldukça iyi olduğunu söyleyebiliriz.

Covid-19 pandemi döneminde sağlık çalışanlarının KKD kullanımları ile ilgili farkındalık artmış olsa da T.C.Sağlık Bakanlığı'nın Ağustos (2020) ayı sonu verilerine göre ülkemizde bir milyon altmış bir bin altı yüz otuz beş sağlık çalışanından ne yazık ki yirmi dokuz bin sekiz yüz altmış beş sağlık çalışanına virüs bulaşmış ve elli iki sağlık çalışanımız da hayatını kaybetmiştir. KKD'lerin doğru kullanımı çalışanın performansını doğrudan etkileyerek bu tür risklerin azaltılmasına katkı sağlayacaktır.

$\mathrm{Bu}$ çalışma ile yeni mezun olan öğrencilerin bize sağlayacağı geri bildirim sonuçları değerlendirilerek var olan durum doğrultusunda eğitim programlarında gerekli düzenlemelerin yapılması sağlanarak doğru KKD kullanımının öğrencilerin bilgi ve beceri yönünden mesleki yeterliklerinde ve dolayısı ile iş sağlığı ve güvenliğinde olumlu katkı sağlayacağına inanılmaktadır.

\section{SONUÇ VE ÖNERILER}

Katılımcıların \%90’ının KKD ve kullanımına ilişkin bilgi kaynaklarının "uygulamalı dersler, staj vb. gibi saha uygulamaları ile "teorik dersler" olduğu belirlenmiştir. Yeni mezun öğrencilerin KKD ile bilgi kaynaklarının üniversite eğitimleri olduğu söylenebilir.
Katılımcıların yaklaşık \%90'ının KKD’ lerin kullanımına ilişkin doğru bilgiye sahip oldukları ve KKD'lerin kullanım nedenleri ile KKD'lerin nelere karşı koruyucu olmadığını bildikleri belirlenmiştir. Katılımcıların büyük bir oranı (\%95) sağlık çalışanı 
için kullanılan KKD' lerin isimlerini doğru açıklamaktadır.

Her on katılımcidan sekizinin Covid-19 pandemisi gibi salgınların olduğu dönemlerde maskenin kullanım talimatı ile ilgili doğru bilgiye sahip oldukları belirlenmiştir.

Her on katılımcıdan dokuzunun cerrahi maske ve kullanım süresini doğru açıkladıkları; ancak KKD'lerden olan "gözlük ve yüz koruyucuları" ile ilgili her on katılımcıdan altısının doğru cevaba sahip oldukları belirlenmiştir.

Yaklaşık her iki katılımcıdan birisi KKD kullanımında giyme sırasını doğru sıralamaktadır.

Katılımcıların yaklaşık \%65'i "cerrahi maske kullanım sırası hakkında"; yaklaşık \% 75'i ise "eldiven kullanımı hakkında" doğru bilgiye sahiptir.

Her üç katılımcıdan birisi Covid-19 gibi yüksek bulaş riski olan enfeksiyon hastalıklarında önlük kullanımı ile ilgili sıralamayı doğru bilmektedirler.

Yaklaşık her iki katılımcıdan birisinin uygulama ve/ veya staj gibi saha çalışmalarında kişisel koruyucu donanımı "her vakada" kullandığı, her üç katılımcıdan birinin de "sıklıkla kullandığı" belirlenmiştir.
Katılımcilara göre; uygulama yapılan birimdeki diğer sağlık çalışanlarının KKD kullanım sıklıkları değişmektedir. Sağlık çalışanlarının \%10'unun "her vakada” KKD kullandığı, yaklaşık $\% 50$ 'sinin ise "sıklıkla" KKD kullandığ gözlenmiştir.

Katılımcıların yarısı KKD kullanımında uygulamadaki gözlemlerinin/rol modellerin kendi KKD kullanımına ilişkin düşüncelerine "çok etkili”" olduğunu söylemiştir.

Saha uygulamalarına giden öğrencilerin, uygulama sürecinde kendi güvenlikleri konusunda yaklaşık her on öğrenciden dördünün "hiç tedirgin" olmadığı, yaklaşık her on öğrenciden altısının ise "biraz tedirgin" olduğu belirlenmiştir. $\mathrm{Bu}$ soruya verilen cevaplara bakarak katılımcıların saha uygulamalarında çalıştıkları ortamlarda kendilerini güvende hissettikleri söylenebilir.

$\mathrm{Bu}$ çalışma ile elde edilen bulgular hem literaratüre katkı sağlamada hem de SHMYO programlarındaki teorik ve uygulamalı derslerin KKD kullanımı ve önemine ağırlık verilecek şekilde düzenlenmesi ile iş sağlığı ve güvenliği uygulamalarında kullanılabilir.

\section{Kisıtlılıklar}

Araştırmanın sınırlılıklarından biri örneklem çapıyla ilgilidir. Bulgular bir büyükşehirde, Vakıf Üniversitesi SHMYO yeni mezun olan öğrencileri (2019-2020 Bahar Dönemi) ile sinırlıdır. Araştırmada uygulama yapılan birimdeki tüm öğrenciler $(\mathrm{N}=39)$ araştırma kapsamına alınmıştır.

$\begin{array}{llrr}\text { Bulgular bu durum } & \text { dikkate } & \text { alınarak } \\ \text { yorumlanmalıdir. } & & \text { Bulgular } & \text { Devlet }\end{array}$

Üniversitesinden yeni mezun olan öğrencilerine genellenemez. Ayrica SHMYO'nun bir programı çalışma kapsamına alınmıştır. Sonraki çalışmalarda diğer programlar da çalışmaya dahil edilebilir. Araştırmada son kısıtlılık çalışmanın Covid-19'un başlangıç döneminde yapılmış olmasidir. 
Çıkar Çatışması: Yazar çıkar çatışması bildirmemiştir.

Finansal Destek Beyanı: Yazar finansal destek bildirmemiştir.

Yazarların Katkısı: Yazı tek yazarlıdır.

\section{REFERANSLAR}

Arsal Y1ldırım, S, Gerdan, S. (2017). Hastane öncesi acil sağlık çalışanlarının iş sağlığı ve güvenliği kapsamındaki mesleki riskleri. Hastane Öncesi Dergisi, 2 (1), 37-49. Retrieved from https://dergipark.org.tr/tr/pub/hod/issue/29287/3139 37

Beşer, A, Topçu, S. (2013). Sağlık Alanında Kişisel Koruyucu Ekipman Kullanımı. Dokuz Eylül Üniversitesi Hemşirelik Fakültesi Elektronik Dergisi, 6 (4) , 241-247 . Retrieved from https://dergipark.org.tr/tr/pub/deuhfed/issue/46812/ 587036

Demirbilek, T, Çakır, Ö. (2016). Kişisel koruyucu donanım kullanımını etkileyen bireysel ve örgütsel değişkenler. Dokuz Eylül Üniversitesi İktisadi İdari Bilimler Fakültesi Dergisi, 23 (2), 173-191. Retrieved from https://dergipark.org.tr/tr/pub/deuiibfd/issue/22740/ 242722

Deveci, S. (2012). Kişisel koruyucu donanım kullanımının iş sağlığg ve güvenliği uygulamalarındaki yeri. Hacettepe Üniversitesi $\dot{I}_{S}$ Să̆llğg ve e Güvenliği, Meslek Hastalıklarl Uygulama ve Araştırma Merkezi, Kişisel Koruyucu Donanım Sempozyumunda sunulmuştur. Ankara. http://www.hisam.hacettepe.edu.tr/sempozyum_sun um/SerolDeveci.pdf Erişim tarihi:11.08.2020

Gazi Üniversitesi (2017). Mezun görüş anketi, http://anket.gazi.edu.tr/graduate, Erişim tarihi, 12.07 .2020

Kahya, E, Ulutaş, B, Özkan, N . (2019). Metal endüstrisinde kişisel koruyucu donanım kullanımının analizi. Selçuk Üniversitesi Mühendislik, Bilim ve Teknoloji Dergisi, 7 (2), 420 433 . DOI: 10.15317/Scitech.2019.209

Karasar, N. (2018). Bilimsel araştırma yöntemi: Kavramlar ilkeler teknikler 33. Bask1. Nobel Akademik Yayıncılık

Metan, G. (2020). Sağlık çalışanları için korunma yöntemleri. Infeksiyon Dünyası Coivd-19 Ĕ̈itim Seti https://www.infeksiyondunyasi.org/covid19videoeg itimseti/VideoView.aspx?id=12 Erişim tarihi:09.07.2020

T.C. Resmî Gazete. İş sağlığı ve güvenliği kanunu. 30 Haziran 2012 Sayı: 28339, Başbakanlık Basımevi

T.C. Resmî Gazete. Kişisel koruyucu donanım yönetmeliği. 1 Mayıs 2019, sayı: 30761, T.C. Cumhurbaşkanlığı İdari İşler Başkanlığı Hukuk ve Mevzuat Genel Müdürlüğü Yayını.

T.C. Resmî Gazete. Kişisel koruyucu donanımların işyerlerinde kullanılması hakkında yönetmelik. 2 Temmuz 2013, sayı: 28695. Başbakanlık Basımevi

Türk Tabipler Birliği Sağlık Çalışanlarının Sağlığı Çalışma Grubu (2014). Sağlık çalışanları için işçi sağlığı ve güvenliği (Yayına hazırlayan: Hasan Oğan) 44-46. Ankara: Türk Tabipleri Birliği Yayın1.

http://www.saglikcalisanisagligi.org/tezler2/scskita bi.pdf Erişim tarihi:6.07.2020 
